\title{
Efficacy comparison between toric intraocular lens and aspheric intraocular lens plus steep-axis incision in cataract patients with low corneal astigmatism
}

\author{
Ziyuan Liu', Ren Zhou ${ }^{2}$, Ke Xu' ${ }^{1}$, Aihua Ding ${ }^{1}$, Wei Wang ${ }^{1}$, Tao Wu ${ }^{2}$, Yanxiu Sun ${ }^{1}$ \\ ${ }^{1}$ Department of Ophthalmology, Peking University Third Hospital, Beijing Key Laboratory of Restoration of Damaged Ocular Nerve, Beijing, \\ China; ${ }^{2}$ Department of Epidemiology and Biostatistics, School of Public Health, Peking University, Beijing, China \\ Contributions: (I) Conception and design: Y Sun, T Wu; (II) Administrative support: Y Sun, W Wang; (III) Provision of study materials or patients: Y \\ Sun, K Xu; (IV) Collection and assembly of data: Z Liu, K Xu, A Ding; (V) Data analysis and interpretation: Y Sun, R Zhou, Z Liu; (VI) Manuscript \\ writing: All authors; (VII) Final approval of manuscript: All authors. \\ Correspondence to: Yanxiu Sun, MD. Peking University Third Hospital, 49 North Garden Road, Haidian District, Beijing 100191, China. \\ Email: yxs0283@yahoo.com.
}

Background The present study aimed to evaluate and compare the efficacy of toric intraocular lens (IOL)
implantation and aspheric IOL implantation with steep-axis incision for correcting mild to moderate corneal
astigmatism in cataract patients.
Methods: A prospective, single-center, open label, randomized, two-arm study was designed. Cataract
patients with corneal astigmatism of 1.0-2.0D were enrolled and divided into test and control groups.
The test group had the AcrySof ${ }^{\circledR}$ IQ Toric IOL implanted and the control group had the AcrySof ${ }^{\circledR}$ IQ
IOL implanted with a steep-axis corneal incision. All patients underwent examinations of uncorrected
distance visual acuity (UCDVA), corrected distance visual acuity (CDVA), subjective refraction, and corneal
astigmatism before surgery and at the 1-day, 1-month, and 3-month follow-ups. Vector astigmatism analysis
was evaluated using the Alpins method.

Results: We enrolled 26 eyes of 20 patients in the study, with 13 eyes in each group. The test group had better vision than the control group at the 3-month follow-up and had more cases with a UCDVA of 20/20 (10/13 vs. 4/13). The surgically induced astigmatism (SIA) vector of the test group was higher than that of the control group $(1.22 \pm 0.64$ vs. $0.84 \pm 0.45)$. The correction index of the test group was closer to 1 compared to that of the control group ( 0.7 vs. 0.46). Approximately $85 \%$ of patients in the test group had an angle of error within $-15^{\circ}$ to $15^{\circ}$. However, only $23 \%$ of patients in the control group were within that range.

Conclusions: Though steep-axis corneal incision was cost-saving and easy-to perform, its astigmatismcorrecting efficacy was not as good as the Toric IOL implantation for cataract patients with low to moderate corneal astigmatism.

Keywords: Corneal steep axis; low astigmatism; toric intraocular lens (toric IOL); uncorrected distance visual acuity (UCDVA)

Submitted Jul 17, 2020. Accepted for publication Dec 03, 2020.

doi: 10.21037/apm-20-1434

View this article at: http://dx.doi.org/10.21037/apm-20-1434

\section{Introduction}

Management of corneal astigmatism is becoming an essential part of present-day cataract surgery. Residual astigmatism can lead to unsatisfactory distance visual acuity and dependence on spectacles postoperatively. Corneal astigmatism is common in cataract patients. An estimated $31.64-50 \%$ of cataract patients exhibiting more than 1.0 diopter (D) of astigmatism (1,2), 29.7\%, 18.03\%, 9.71\% 
and $2.65 \%$ have astigmatism more than $1.25 \mathrm{D}, 1.5 \mathrm{D}$, 2.0D and 3.0D respectively (2,3). Most older people have against-the-rule astigmatism that can cause obvious visual disturbance even with a low degree. Low astigmatism (e.g., $0.5 \mathrm{D})$ can decrease vision by one line on the logarithm of the minimum angle of resolution (LogMAR) chart, and astigmatism $>0.75 \mathrm{D}$ can result in blurry or double vision.

Current treatments for cataract combined with corneal astigmatism include toric intraocular lens (IOL) implantation and non-toric IOL with incisional-based interventions such as limbal relaxing incision (LRI), astigmatic keratectomy (AK), and steep-axis incision (4-7). Both toric IOL and incisional-based methods have strengths and shortcomings, and their respective efficacy and cost have long been discussed.

Toric IOLs are used for a wide range of astigmatism, from $0.75 \mathrm{D}$ to $6 \mathrm{D}$. Levitz investigated the use of low-power toric IOLs in patients with a corneal cylinder of $<1.25 \mathrm{D}$ and suggested it could achieve excellent outcomes (8). Mairot et al. compared the refractive predictability of low-power and medium-power toric IOLs in cataract surgery and found that both groups had extremely good refractive results (9). However, with a higher cost and a risk of rotation, the toric IOL is not routinely used for low astigmatism.

Steep-axis incision is an economical and time-saving method that can be easily performed during cataract surgery. It is reported to correct $0.5-1.5 \mathrm{D}$ astigmatism, but the long-term stability and predictability are controversial.

The optimal method for treating eyes with astigmatism $<2.0 \mathrm{D}$ has not been determined. In this study, we aimed to analyze and compare the correcting efficacy between toric IOL implantation and aspheric IOL implantation with a steep-axis corneal incision in patients with a corneal cylinder of 1.0-2.0D, in the hope of gaining information that could guide decision-making for the management of low astigmatism.

We present the following article in accordance with the CONSORT reporting checklist (available at http://dx.doi. org/10.21037/apm-20-1434).

\section{Methods}

\section{Subjects}

All patients were diagnosed as having cataract with corneal astigmatism ranging from $1.0 \mathrm{D}$ to $2.0 \mathrm{D}$ in the Department of Ophthalmology of Peking University Third Hospital and required surgical treatment. The inclusion criteria were:
(I) age-related cataract; (II) regular corneal astigmatism of 1.0-2.0D; (III) normal ocular length of 22.0-24.5 mm measured with IOL Master or A-ultrasound when severe lens opacity prevented IOL Master from working; (IV) pupil could be dilated to $6 \mathrm{~mm}$ to facilitate postoperative observation and measurement of the axial direction of the IOL; and (V) goal of emmetropia. Furthermore, the patients had to be physically healthy and able to complete follow-up visits for 3 months. The exclusion criteria were: (I) a history of ophthalmic surgery; (II) accompanied by glaucoma, fundus diseases, or other eye diseases that might affect postoperative vision; (III) severe dry eye; and (IV) irregular corneal astigmatism. Informed consent was given by all participants, and the study was approved by the Ethical Committee of Peking University Third Hospital (M2016136). Investigations were conducted in accordance with the tenets of the Declaration of Helsinki (as revised in 2013).

\section{Sample size}

Calculation of the required sample size was based on the following assumptions: the difference between the test and control groups regarding reducing the corneal astigmatism of patients was 0.6 ; the standard deviation of the corneal astigmatism reduction after surgery was $0.7 ; \alpha$ was set as 0.05 and $\beta$ was set as 0.10 . The smallest required sample size was 24, with 12 patients each in the test and control groups. Thus, we chose to enroll 26 patients for the two groups, at a ratio of $1: 1$.

\section{Intervention}

The patients were divided into two groups using the sealed envelope method: 26 random numbers were generated by computer and assigned to the test and control groups at a ratio of 1:1. Numbered cards were sealed in identical envelopes with numbers from 1 to 26. Participants who met the inclusion criteria selected an envelope to obtain a random number and were grouped accordingly. Patients in the test group were implanted with a toric IOL (AcrySof ${ }^{\circledR}$ IQ Toric IOL, Alcon Inc.) and the control group with a single-focus aspheric IOL (AcrySof ${ }^{\circledR}$ IQ Aspheric IOL, Alcon Inc.). Patients with binocular cataracts had their eyes enrolled separately and randomly. The corneal incision of the test group was made at the axis of $135^{\circ}$, and that of the control group was situated at the steep axis of the cornea.

All procedures were performed by the same skilled 
surgeon (Dr. Sun) and were conducted under surface anesthesia. The location of the incision and the axis of the toric IOL were guided by an intraoperative navigation system (Zeiss Callisto Eye, Germany). The operations were carried out through a transparent corneal incision of $2.8 \mathrm{~mm}$; the incisions of both groups were made as described above. The location of incisions were settled by IOL MASTER 500 (Zeiss, Germany) during the operation. Viscoelastic agent (DisCoVisc, Alcon, USA) was injected into the anterior chamber, and the continuous circular capsulorhexis technique was used. Conventional ultrasonic emulsification was successfully performed (Centurion, Alcon, USA) and then the IOL was implanted with the MONARCH III IOL injector (Alcon, USA). The toric IOL in the test group was rotated clockwise to $\sim 10^{\circ}$ from the preset axial position. The viscoelastic agent was removed, and the axial position was finely adjusted to the preset axial position under the guidance of the navigation system.

\section{Assessment of outcomes}

Before the operation, all participants underwent uncorrected distance visual acuity (UCVA), corrected distance visual acuity (CDVA), subjective refraction, intraocular pressure (IOP Canon TX-F, Japan), and corneal curvature (Topcon, KR-8100PA, Japan) measurement, slit-lamp examination, color fundus photography (Canon CR-2AF, Japan), optical coherence tomography [Zeiss Cirrus HD-OCT (40007943), Germany], corneal topography (Pentacam, HR Typ70900, Germany), A-ultrasound (Alcon, USA), biomeasurement (Zeiss, IOL MASTER 500, Germany), and corneal endothelial cell counting (Topcon, SP.3000P, Japan). The Haigis formula was used for IOL calculation: when the target diopter is between 0 and 0.4 , the value closest to 0 is selected. The Barrett Toric Calculator was chosen as the formula for cylinder calculation for eyes with against-the-rule astigmatism on the posterior surface, which was measured by corneal topography. When against-therule astigmatism was excluded, the original Alcon Toric Calculator was selected. The toric IOL rotation in the test group was calculated using the Toricam App (Graham D Barrett).

At 1 day, 1 week, 1 month, and 3 months post operation, the patients underwent measurement of UCDVA, CDVA, subjective refraction, IOP, and corneal curvature (with auto kerato-refractometer at each follow-up visit and IOL MASTER at the 3-month follow-up). To detect the IOL axis position, anterior segment photography was performed of a dilated pupil in the test group. If the toric IOL had rotated more than $10^{\circ}$, surgical re-alignment was required.

\section{Statistical analysis}

The sample size in this study was calculated according to the data from the published literature and adjusted according to an expected failure rate of $20 \%$. Finally, 26 eyes were included in the analysis, with 13 eyes in each group. All variables were described as the mean value and standard deviation, and the data were analyzed with SPSS 22.0 statistical software. The main evaluation indexes included the average degree of cylinder refraction, corneal astigmatism, UCDVA, and CDVA. The data of each group were firstly verified by homogeneity of variance and normal distribution. Moreover, an independent sample $t$-test was used for comparisons between groups for normally distributed data, and the nonparametric Mann-Whitney $U$ test was applied for comparison of non-normally distributed data. Finally, the Mann-Whitney $U$ test was used for analysis and comparison of total astigmatism and visual acuity after surgery, and the $t$-test was applied for analysis and comparison of corneal astigmatism after surgery.

\section{Results}

Twenty-six eyes (in 20 patients) were included in the study. There were no surgical complications, nor did any of the patients require surgical alignment for toric IOL rotation. All participants completed the follow-up. Demographic and preoperative data showed no significant differences between the two groups (Table 1). Details of visual acuity improvement and astigmatism correction were demonstrated in Figure 1. Astigmatism was further analyzed in single-angle polar plots in Figure 2.

\section{Visual acuity}

Postoperative UCVA (LogMar) values are listed in Table 2. There was no significant difference in UCVA between the two groups at the 1-day, 1-week, or 1-month followup. However, at 3 months postoperatively, the UCVA of the test group was 0.03 , compared with 0.13 in the control group $(\mathrm{P}=0.033)$. With toric IOL implantation, the test group achieved better vision after the operation compared with the control. At the 3-month follow-up, there were 12 cases $(12 / 13,92.3 \%)$ with UCDVA better than $20 / 25$ and 10 cases $(10 / 13,76.9 \%)$ with UCDVA of $20 / 20$ or better 
Table 1 Demographic and preoperative biological measurements

\begin{tabular}{|c|c|c|c|}
\hline Demographic/biological measurements & Test & Control & $P$ value \\
\hline Age (year) & $74 \pm 5.7$ & $71 \pm 9.2$ & 0.43 \\
\hline Gender (M/F, n) & $6 / 7$ & $4 / 9$ & - \\
\hline Length (mm) & $23.37 \pm 0.76$ & $23.16 \pm 0.91$ & 0.63 \\
\hline \multicolumn{4}{|l|}{$\mathrm{CA}(\mathrm{D})$} \\
\hline Anterior surface & $1.52 \pm 0.24$ & $1.53 \pm 0.23$ & 0.92 \\
\hline WTR (n) & 4 & 1 & \\
\hline $\operatorname{ATR}(n)$ & 9 & 12 & \\
\hline $\mathrm{O}(\mathrm{n})$ & 0 & 0 & \\
\hline $\operatorname{ATR}(n)$ & 10 & 10 & \\
\hline$O(n)$ & 1 & 1 & \\
\hline IOL SD & $22.13 \pm 1.25$ & $21.61 \pm 2.19$ & 0.57 \\
\hline IOL CD & $1.48 \pm 0.38$ & & \\
\hline
\end{tabular}

CA, corneal astigmatism; WTR, with the rule; ATR, against the rule; O, oblique; IOL SD, intraocular lens spherical diopter; IOL CD, intraocular lens cylinder diopter.

in the test group. In the control group, there were 8 cases $(8 / 13,61.5 \%)$ with UCDVA better than $20 / 25$ and 4 cases (4/13, 30.8\%) with UCDVA of 20/20 or better (Figure 1A).

A comparison of CDVA is shown in Table 2. There was no significant difference between the CDVA of the two groups in the follow-up visits.

Approximately $92 \%$ of the patients in the test group had UCVA within one line of the CDVA and 54\% had UCVA that was the same as the CDVA. In the control group, only $69 \%$ of patients had UCVA within one line of the CDVA and $46 \%$ had UCVA that was the same as the CDVA (Figure 1B). In both groups, a majority of patients had gained $\geq 3$ lines of CDVA at 3 months after surgery (Figure 1C).

\section{Spherical equivalent refraction}

Attempted and achieved spherical equivalent refraction at 3 months after surgery was analyzed, and no statistical difference was found between the two groups (Table 3).

\section{Astigmatism}

Table 2 shows a comparison of anterior corneal astigmatism between the two groups. No statistical difference was observed between the two groups in terms of preoperative corneal astigmatism. At the 1-month follow-up, the corneal astigmatism of the test group was higher than that of the control group $(\mathrm{P}=0.035)$, but no other significant difference was observed.

At 3 months after the operation, there were 4 cases $(4 / 13,31 \%)$ of cylinder $<0.5 \mathrm{D}$ and 11 cases $(11 / 13,85 \%)$ of cylinder $<1.0 \mathrm{D}$ in the test group. In the control group, there was 1 case $(1 / 13,8 \%)$ of cylinder $<0.5 \mathrm{D}$ and 2 cases $(2 / 13,15 \%)$ of cylinder $<1.0 \mathrm{D}$ (Figure $1 D)$.

Target induced astigmatism (TIA) and surgically induced astigmatism (SIA) are shown in single-angle polar plots based on the Alpins method (Figure 2). The TIA of the test group and control group was $1.53 \pm 0.25$ and $1.53 \pm 0.23$, respectively, and the difference was not significant $(\mathrm{P}=0.95)$. The SIA of the test group $(1.22 \pm 0.64)$ was higher than that of the control group $(0.84 \pm 0.45)$, although the difference was not significant $(\mathrm{P}=0.093)$.

The correction index of the test group (geom. mean $=0.7$ ) was closer to 1 than that of the control group (geom. mean $=0.46)$ (Figure 2D). More cases in the control group were under-corrected, and the test group showed better 


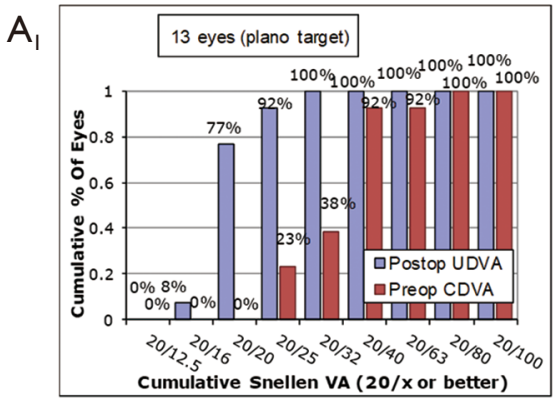

Uncorrected Distance Visual Acuity

$D_{1}$

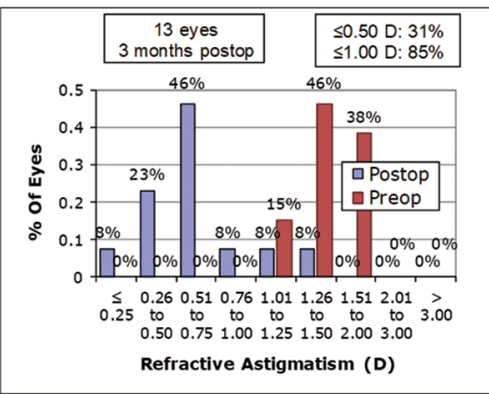

Refractive Astigmatism

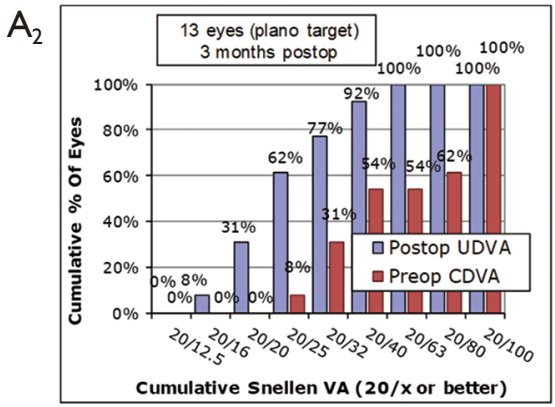

Uncorrected Distance Visual Acuity

$\mathrm{D}_{2}$

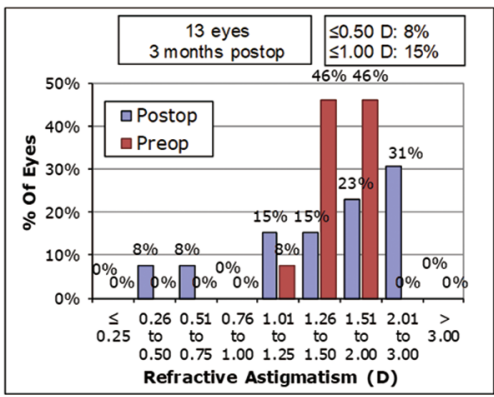

Refractive Astigmatism
$B_{1}$

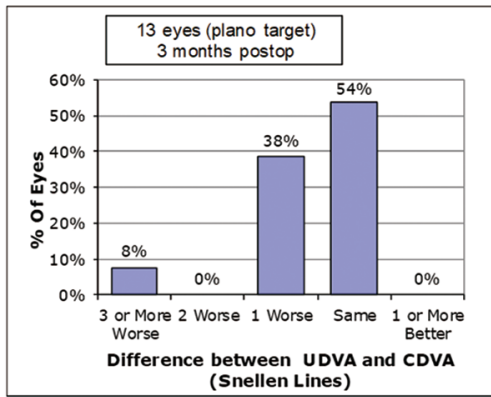

Uncorrected Distance Visual Acuity vs. Corrected Distance Visual Acuity

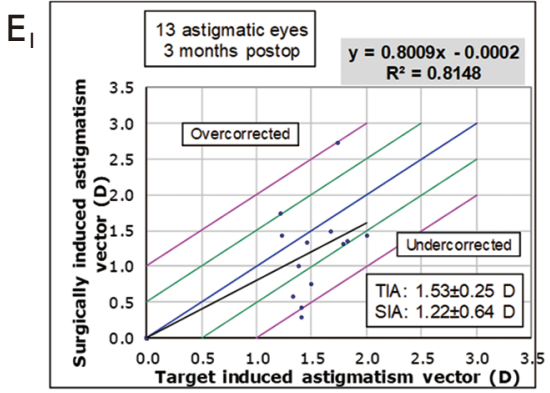

Target Induced Astigmatism vs. Surgically Induced Astigmatism

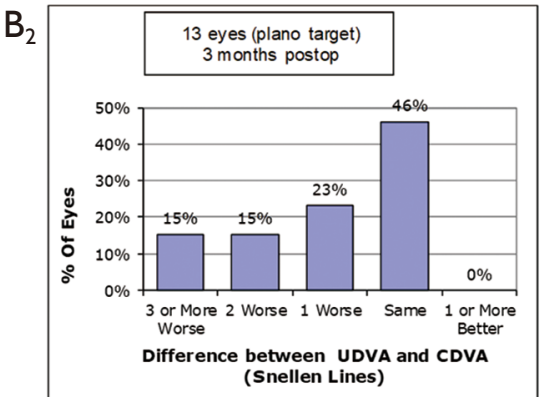

Uncorrected Distance Visual Acuity vs. Corrected Distance Visual Acuity

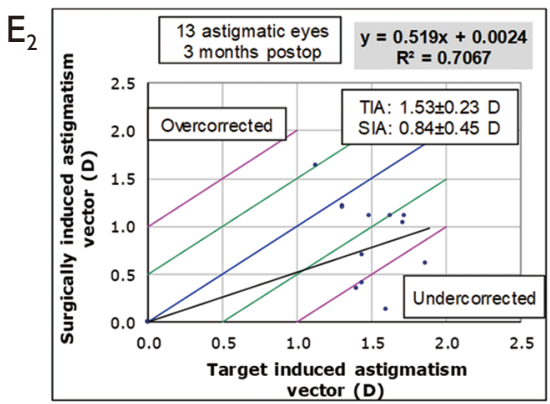

Target Induced Astigmatism vs. Surgically Induced Astigmatism

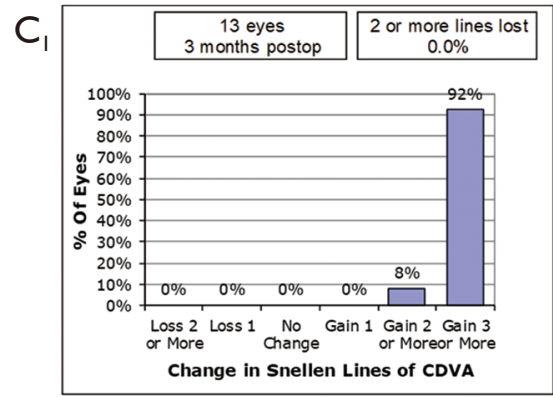

Change in Corrected Distance Visual Acuity

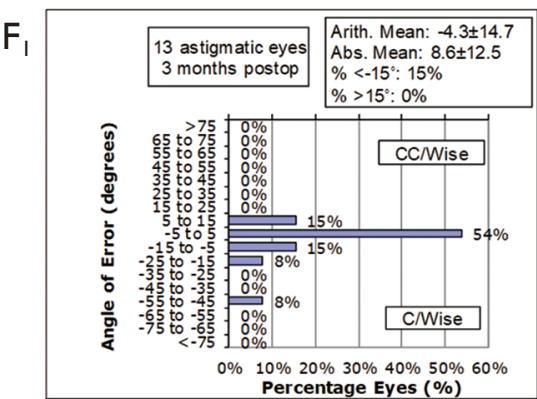

Refractive Astigmatism Angle of Error

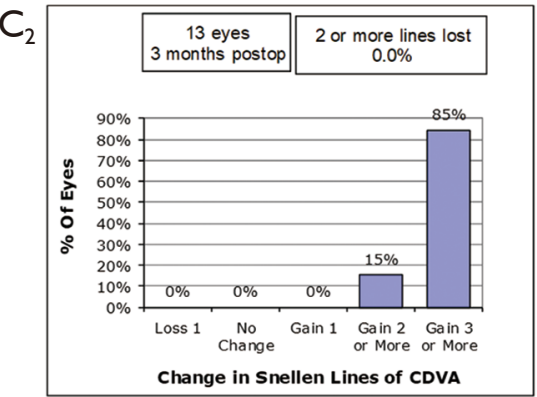

Change in Corrected Distance Visual Acuity

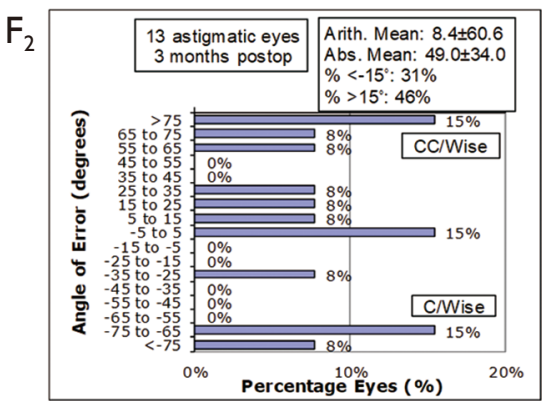

Refractive Astigmatism Angle of Error

Figure 1 (A,B,C) Details of visual acuity at 3 months after cataract surgery. (A) Cumulative UCDVA: the test group had more cases of UCDVA better than 20/25. (B) Improvement in postoperative UCDVA compared with CDVA before the surgery. (C) Change in CDVA compared with before surgery. (D,E,F) Details of astigmatism correction. (D) Status at 3 months after surgery. (E) Analysis of under- and overcorrection. (F) Distribution of angle of error. CDVA, corrected distance visual acuity; UCDVA, uncorrected distance visual acuity. 

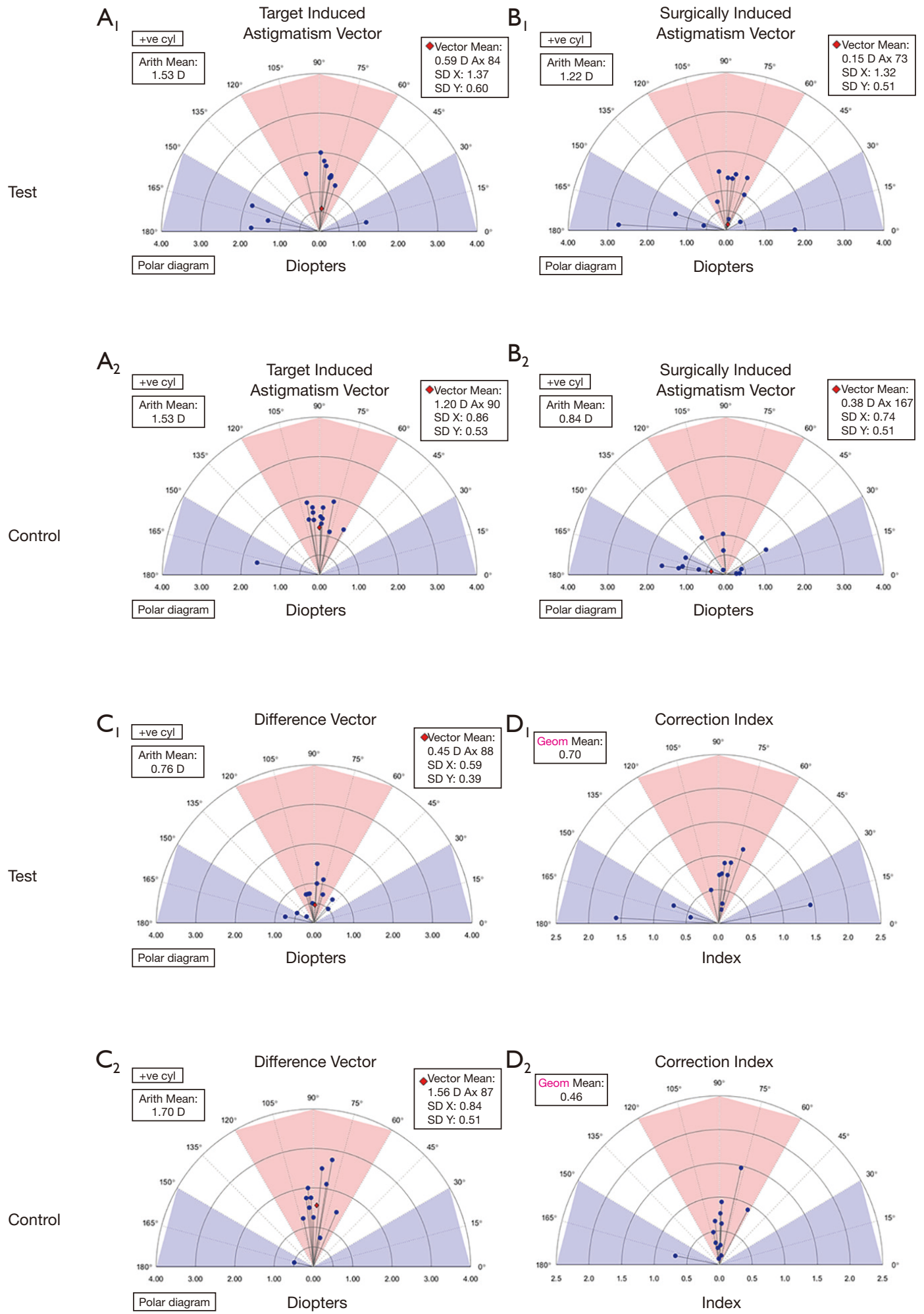

Figure 2 Single-angle polar plots for the target-induced astigmatism vector (TIA), surgically induced astigmatism vector (SIA), difference vector, and correction index. The vector means are plotted as a red diamond. 
Table 2 Visual acuity and anterior corneal surface astigmatism changes post surgery

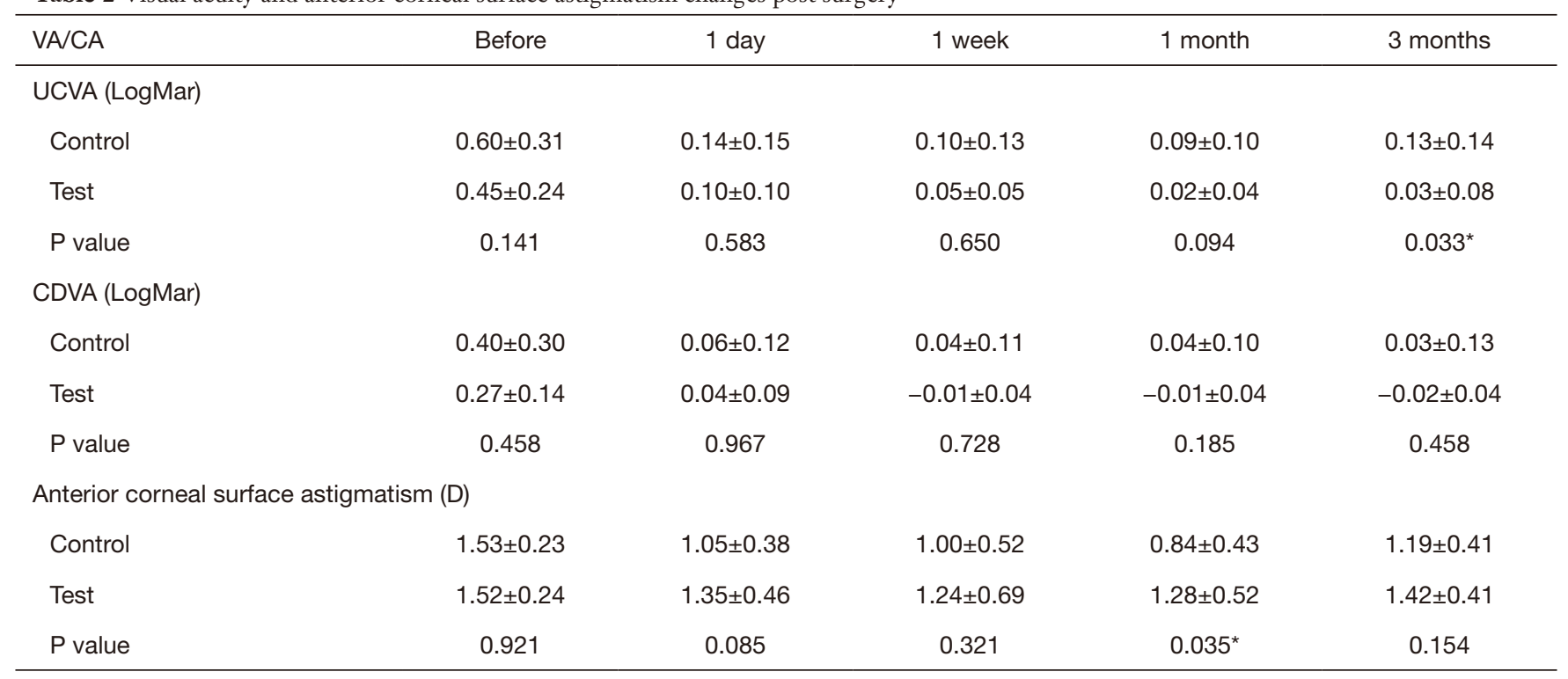

Mann-Whitney test. * $\mathrm{P}<0.05$. VA, visual acuity; CA, corneal astigmatism; CDVA, corrected distance visual acuity; UCVA, uncorrected distance visual acuity.

Table 3 Spherical equivalent refraction 3 months after surgery

\begin{tabular}{lccc}
\hline SE & Test & Control & $P$ value \\
\hline Attempted & $-0.19 \pm 0.18$ & $-0.19 \pm 0.12$ & 0.95 \\
Achieved & $0.14 \pm 0.49$ & $0.12 \pm 0.45$ & 0.92 \\
Absolute achieved SE & $0.39 \pm 0.31$ & $0.33 \pm 0.32$ & 0.64 \\
SE error & $0.35 \pm 0.45$ & $0.54 \pm 0.40$ & 0.28 \\
Absolute SE error & $0.45 \pm 0.34$ & $0.54 \pm 0.39$ & 0.55 \\
\hline
\end{tabular}

Independent sample $t$-test. SE, spherical equivalent.

correction of astigmatism (Figure 1E).

The difference vector showed that the remaining astigmatism in the test group was much smaller than that in the control group (Figure 2C). The angle of error is shown in Figure $1 \mathrm{~F}$. Approximately $85 \%$ patients in the test group had an angle of error within $-15^{\circ}$ to $15^{\circ}$, but only $23 \%$ eyes in the control group had angle of error within that range. The absolute mean of the angle of error in the test group was $8.6 \pm 12.5$, compared with $49.0 \pm 34.0$ in the control group.

No posterior capsule opacity was observed in any of the patients during follow-up. The toric IOL rotation was detected: 4 counterclockwise and 9 clockwise. The absolute mean rotation was $4.23 \pm 3.24$.

\section{Discussion}

As one of the leading causes of visual deterioration, astigmatism is usually corrected through wearing spectacles. However, for cataract patients, astigmatism can also be corrected by removing the opaque lens and implanting an IOL, which can give patients better quality vision postoperatively without spectacles. Thus, in recent years, surgical procedures to correct astigmatism during cataract surgery have evolved dramatically $(4,10,11)$.

LRI was an early surgical method to improve corneal astigmatism and is considered to be safer and less complicated than other surgical methods. According to Hayashi's report, the longer the corneal release incision, the 
better the correcting effect on the astigmatism; however, this effect becomes weaker with time (12). Opposite clear corneal incisions can correct astigmatism by $\sim 0.5-1.66 \mathrm{D}$, and a clear corneal incision can correct astigmatism by $\sim 0.4-0.8 \mathrm{D}(13,14)$

Astigmatism-correcting IOLs have improved rapidly since 1988, when the first IOL combining spherical power and astigmatism correction appeared. At present, toric IOLs are the mainstream choice for correcting moderate to high astigmatism in cataract surgery. Compared with LRI surgery, toric IOL implantation can reduce surgical complications, with good long-term stability and predictability of postoperative refractive status, especially for patients with moderate to high astigmatism (5,15-18). Making a steepaxis corneal incision during cataract surgery can avoid additional procedures of relaxing incision, thus reducing the risk of surgical complications as well as cost. As a less expensive and simpler procedure, corneal incision at steepaxis could become a widely used method to correct low corneal astigmatism in cataract surgery. Giansanti et al. (19) and Yang et al. (20) reported that corneal incisions of 2.75, 2.2 , and $1.8 \mathrm{~mm}$ at a steep axis could correct astigmatism of $0.32 \mathrm{D}, 0.27 \mathrm{D}$, and $0.25 \mathrm{D}$, respectively. However, whether this method could be used in patients with low corneal astigmatism has yet to be determined.

We compared the effectiveness and stability of toric IOL implantation and a steep corneal axis incision for correcting low-grade corneal astigmatism in eyes with cataract, mainly by evaluating postoperative vision and refractive status.

Postoperative UCDVA is more clinically significant than CDVA, as it determines the postoperative need for spectacles. Our results showed that the postoperative UCDVA of the test group at the 3-month follow-up was better than that of the control group. At the same followup, the rate of UCDVA better than 20/25 the control and test groups was $61.5 \%$ and $92.3 \%$, respectively, and that of UCDVA of $20 / 20$ or better was $23.1 \%$ and $53.8 \%$ respectively. The CDVA of the two groups was significantly improved compared with that before the operation, and there was no statistical difference between the groups. These findings are similar to the results of previous studies, but the final UCDVA of the two groups in this study was higher than that reported in the literature, which may be attributable to improvements in biological measuring instruments and calculation formulas as well as the assistance of surgical navigation equipment $(6,17,21)$.

In the test group, $85 \%$ of cases had astigmatism $<1 \mathrm{D}$ at 3 months after surgery, but the control group had only
$15 \%$ of similar cases. The SIA of the test group was higher than that of the control group, although the difference was not significant. The correction index of the test group was closer to 1 than that of the control group, suggesting that the outcomes in the test group were better aligned with the surgical aim. Most of the cases in the control group were under-corrected. In terms of the angle of error, $85 \%$ of cases in the test group were within $-15^{\circ}$ and $15^{\circ}$, and $54 \%$ were within $-5^{\circ}$ to $5^{\circ}$; however, in the control group, only $15 \%$ of cases were within $-5^{\circ}$ to $5^{\circ}$, and $23 \%$ were within $-15^{\circ}$ to $15^{\circ}$. At the 3 -month follow-up, the toric IOLs showed limited rotation. Therefore, the test group achieved a better correcting effect than the control group.

The control group had the corneal curvature changed by incision to correct astigmatism. The postoperative astigmatism in the control group showed a decreasing trend and was less than that of the test group at 1 month after the operation. However, no statistical difference was detected at 3 months after surgery, indicating that the longterm stability of this method for improving astigmatism was poor. Despite being a low-cost and simple method, steepaxis corneal incision had obvious inefficiency that could not be overcome, and the toric IOL was much more reliable in achieving the desired effect.

In this study, the axial length of the surgical eye was specifically limited to $22.0-24.5 \mathrm{~mm}$ in order to avoid the effect on the UCDVA caused by the postoperative residual spherical lens power. The normal axial length ensured that most calculation formulas would obtain stable results. Thus, there was no significant difference in equivalent spherical power between the two groups at 3 months after the operation, which suggests that the UCDVA difference observed in this study was not associated with IOL calculation or residual spherical power.

\section{Study limitations}

The present study has some limitations. First, this was a single-center study conducted in a grade III-A hospital, which affects its representativeness of the general population. The efficacy of the toric IOL should be further evaluated and validated in a large-scale multicenter study. Further studies should include more participants and a longer follow-up. Also, the scope of the ocular axial length could be expanded, and patients with even lower astigmatism should be analyzed to see if the same conclusions can be reached. Before treating lower-grade astigmatism, the types of anterior and posterior surface 
astigmatism should be considered.

\section{Conclusions}

The use of steep-axis corneal incision to correct low corneal astigmatism in cataract surgery was neither efficient nor stable and should not be considered for the management of this condition. Toric IOL implantation can achieve smaller residual astigmatism and better UCDVA for cataract patients with low corneal astigmatism of 1.0-2.0D. Future studies involving more cases and longer follow-up will be helpful to confirm our conclusions.

\section{Acknowledgments}

Funding: None.

\section{Footnote}

Reporting Checklist: The authors have completed the CONSORT reporting checklist. Available at http://dx.doi. org/10.21037/apm-20-1434

Data Sharing Statement: Available at http://dx.doi. org/10.21037/apm-20-1434

Conflicts of Interest: All authors have completed the ICMJE uniform disclosure form (available at http://dx.doi. org/10.21037/apm-20-1434). The authors have no conflicts of interest to declare.

Ethical Statement: The authors are accountable for all aspects of the work in ensuring that questions related to the accuracy or integrity of any part of the work are appropriately investigated and resolved. Informed consent was given by all participants, and the study was approved by the Ethical Committee of Peking University Third Hospital (M2016136). Investigations were conducted in accordance with the tenets of the Declaration of Helsinki (as revised in 2013).

Open Access Statement: This is an Open Access article distributed in accordance with the Creative Commons Attribution-NonCommercial-NoDerivs 4.0 International License (CC BY-NC-ND 4.0), which permits the noncommercial replication and distribution of the article with the strict proviso that no changes or edits are made and the original work is properly cited (including links to both the formal publication through the relevant DOI and the license). See: https://creativecommons.org/licenses/by-nc-nd/4.0/.

\section{References}

1. Visco DM, Bedi R, Packer M. Femtosecond laser-assisted arcuate keratotomy at the time of cataract surgery for the management of preexisting astigmatism. J Cataract Refract Surg 2019;45:1762-9.

2. Zvorničanin J. Corneal astigmatism in cataract surgery patients from Bosnia and Herzegovina. Int Ophthalmol 2019;39:1753-60.

3. Wang $\mathrm{Y}, \mathrm{Ke} \mathrm{M}$, Zheng T, et al. Corneal astigmatism among 2085 age-related cataract patients before surgery. Zhonghua Yan Ke Za Zhi 2017;53:522-7.

4. Rubenstein JB, Raciti M. Approaches to corneal astigmatism in cataract surgery. Curr Opin Ophthalmol 2013;24:30-4.

5. Mingo-Botín D, Munoz-Negrete FJ, Won KH, et al. Comparison of toric intraocular lenses and peripheral corneal relaxing incisions to treat astigmatism during cataract surgery. J Cataract Refract Surg 2010;36:1700-8.

6. Nanavaty MA, Bedi KK, Ali S, et al. Toric Intraocular Lenses Versus Peripheral Corneal Relaxing Incisions for Astigmatism Between 0.75 and 2.5 Diopters During Cataract Surgery. Am J Ophthalmol 2017;180:165-77.

7. Ferreira TB, Ribeiro FJ, Pinheiro J, et al. Comparison of Surgically Induced Astigmatism and Morphologic Features Resulting From Femtosecond Laser and Manual Clear Corneal Incisions for Cataract Surgery. J Refract Surg 2018;34:322-9.

8. Levitz L, Reich J, Roberts K, et al. Evaluation of Toric Intraocular Lenses in Patients With Low Degrees of Astigmatism. Asia Pac J Ophthalmol (Phila) 2015;4:245-9.

9. Mairot A, El CH, Agard E, et al. Low-power versus medium-power toric intraocular lenses in cataract surgery, about 110 eyes. J Fr Ophtalmol 2018;41:302-7.

10. Tan QQ, Liao X, Lan CJ, et al. Comparison of Toric intraocular lenses and corneal incisional procedures for correction of low and moderate astigmatism during cataract surgery: A meta-analysis. Zhonghua Yan Ke Za Zhi 2019;55:522-30.

11. Ren Y, Fang X, Fang A, et al. Phacoemulsification With 3.0 and $2.0 \mathrm{~mm}$ Opposite Clear Corneal Incisions for Correction of Corneal Astigmatism. Cornea 2019;38:1105-10.

12. Hayashi K, Yoshida M, Hirata A, et al. Changes in shape and astigmatism of total, anterior, and posterior cornea 
after long versus short clear corneal incision cataract surgery. J Cataract Refract Surg 2018;44:39-49.

13. Ben Simon GJ, Desatnik H. Correction of pre-existing astigmatism during cataract surgery: comparison between the effects of opposite clear corneal incisions and a single clear corneal incision. Graefes Arch Clin Exp Ophthalmol 2005;243:321-6.

14. Khokhar S, Lohiya P, Murugiesan V, et al. Corneal astigmatism correction with opposite clear corneal incisions or single clear corneal incision: comparative analysis. J Cataract Refract Surg 2006;32:1432-7.

15. Muftuoglu IK, Aydin AY, Aksoy S, et al. Comparison of astigmatism correction using either peripheral corneal relaxing incisions or toric intraocular lenses. EUR J Ophthalmol 2016;26:236-41.

16. Leon P, Pastore MR, Zanei A, et al. Correction of low corneal astigmatism in cataract surgery. Int J Ophthalmol 2015;8:719-24.

17. Mendicute J, Irigoyen C, Ruiz M, et al. Toric intraocular

Cite this article as: Liu Z, Zhou R, Xu K, Ding A, Wang W, Wu T, Sun Y. Efficacy comparison between toric intraocular lens and aspheric intraocular lens plus steep-axis incision in cataract patients with low corneal astigmatism. Ann Palliat Med 2021;10(3):2610-2619. doi: 10.21037/apm-20-1434 lens versus opposite clear corneal incisions to correct astigmatism in eyes having cataract surgery. J Cataract Refract Surg 2009;35:451-8.

18. Liu Z, Sha X, Liang X, et al. Toric intraocular lens vs. peripheral corneal relaxing incisions to correct astigmatism in eyes undergoing cataract surgery. Eye Sci 2014;29:198203.

19. Giansanti F, Rapizzi E, Virgili G, et al. Clear corneal incision of $2.75 \mathrm{~mm}$ for cataract surgery induces little change of astigmatism in eyes with low preoperative corneal cylinder. Eur J Ophthalmol 2006;16:385-93.

20. Yang J, Wang X, Zhang H, et al. Clinical evaluation of surgery-induced astigmatism in cataract surgery using $2.2 \mathrm{~mm}$ or $1.8 \mathrm{~mm}$ clear corneal micro-incisions. Int J Ophthalmol 2017;10:68-71.

21. Holland E, Lane S, Horn JD, et al. The AcrySof Toric intraocular lens in subjects with cataracts and corneal astigmatism: a randomized, subject-masked, parallel-group, 1-year study. Ophthalmology 2010;117:2104-11. 